\title{
Isoperistaltic versus antiperistaltic uncut Roux-en-Y anastomosis after distal gastrectomy for gastric cancer: a propensity score matched analysis
}

\author{
Cui Hangtian ${ }^{1+}$, Huang Huabing ${ }^{2 \dagger}$, Luo Tianhang ${ }^{1 \dagger}$, Yin Xiaoyi ${ }^{1}$ and Fang Guoen ${ }^{1,3^{*}}$ (D)
}

\begin{abstract}
Background: The uncut Roux-en-y anastomosis (URYA) has some clinical advantages after distal gastrectomy (DG). Little evidence exists regarding the influence of peristalsis on this anastomosis. We aimed to evaluate short-term outcomes of isoperistaltic URYA (iso-URYA) comparing with antiperistaltic URYA (anti-URYA) after DG.

Method: Patients who underwent URYA for gastric cancer (GC) between January 2016 and December 2018 were selected from Shanghai Changhai Hospital, Navy Medical University. Short-term outcomes were compared between iso-URYA group and anti-URYA group after 1:1 propensity score matching (PSM).

Result: A total of 612 patients were selected. 392 patients underwent iso-URYA and 220 patients underwent antiURYA. After PSM, 183 patients for each group were included in the final analysis. No differences were found between them in terms of short-term complications, nutritional status and quality of life 1 year after surgery. Endoscopic examination showed that anti-URYA group had more severe gastritis $(P=0.036)$. In addition, the recanalization rate was significantly higher when the afferent loop was blocked by stapler.

Conclusion: The iso-URYA and anti-URYA group present similar results in short term outcomes. Ligation blocking afferent loop leads to lower recanalization rate.
\end{abstract}

Keywords: Distal gastrectomy, Uncut Roux-en-Y anastomosis, Propensity score matching

\section{Background}

Gastric cancer is the fifth common cancer globally and its incidence is increasing [1]. Surgical resection with radical lymphadenectomy is regarded as the basic treatment principle for patients with resectable locally advanced gastric cancer [2], while multiple variations have been detailed in the digestive reconstruction. In recent years,

\footnotetext{
*Correspondence: fangguoen888@163.com

${ }^{\dagger} \mathrm{Cui}$ Hangtian, Huang Huabing and Luo Tianhang contributed equally to this work

${ }^{3}$ Department of General Surgery, Changhai Hospital, No.168 Changhai Road, Yangpu District, Shanghai 200433, China

Full list of author information is available at the end of the article
}

many studies indicated that uncut Roux-en-y anastomosis (URYA) after DG had some clinical advantages compared with Billroth I (BI), Billroth II (BII), BII with Braun and Roux-en-Y (RY) reconstruction [3-6]. The reason behind this lies in that URYA can maintain the integrity of the intestinal canal and further preserve myoneural continuity to eliminate Roux stasis syndrome through an occluded but not cut jejunogastric pathway $[7,8]$. Despite this consensus, the operative details vary among surgeons, like ligation or stapler for luminal occlusion, site of occlusion, orientation of peristalsis. Actually, as far as we know, there are still no studies to evaluate functional effects of orientation of peristalsis on URYA. 
In view of this uncertainty, we designed this retrospective study to evaluate the effects of iso- and antiURYA after DG. Propensity score matching (PSM) was used with enough and appropriate subset of covariates to adjust the biased cohort. Short-term outcomes were compared between iso-URYA and anti-URYA after DG for gastric cancer.

\section{Method}

\section{Study design}

This retrospective study has been approved by the Research Ethics Committee of Changhai Hospital, Navy Medical University. The inform consent was exempted in this retrospective study. Demographic baseline and surgical variables of the patients who received DG at Changhai Hospital, Navy Medical University of China during
January 2016 and December 2018 were retrospectively collected in this study. All surgeries were performed by four professors with equivalent experiences in the surgical treatment of gastric cancer. The exclusion criteria were: ASA-IV status, Synchronous malignant diseases, combined surgery and missing data for estimation of propensity score (Fig. 1).

Through a consensus meeting involving surgeons and biostatisticians, 15 preoperative variables possibly influencing the choice of surgical approach and associated with outcome were identified to enable strict PSM. Each patient' s propensity score was calculated using a logistic regression model based on age, sex, area, education, body mass index (BMI), operation year, ASA score, operation history, comorbidity, preoperative chemotherapy, preoperatively measured tumor size, clinical T-stage,

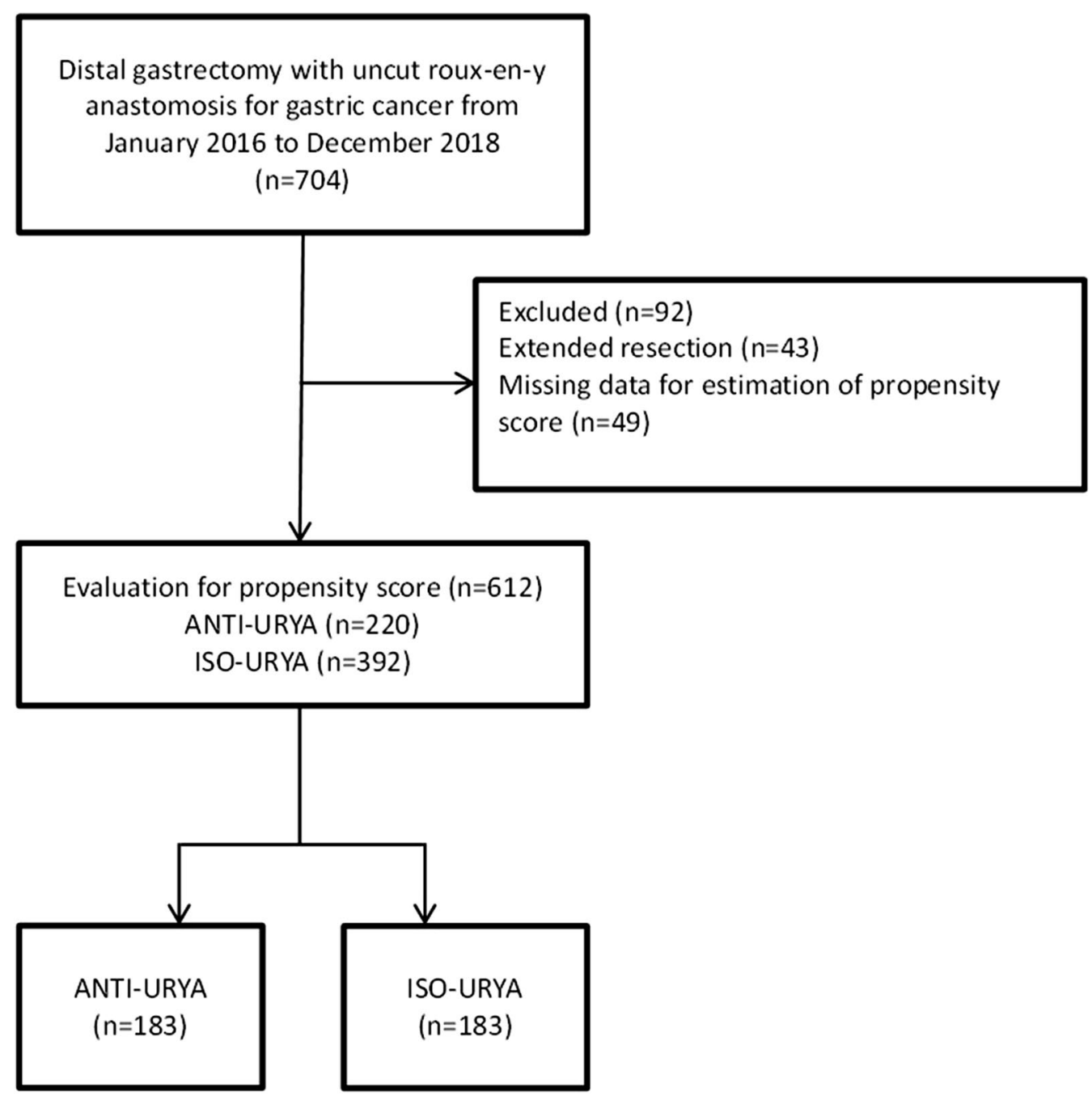

Fig. 1 Flow chart 
clinical N-stage, laparoscopic-assisted or open gastrectomy. Patients in iso-URYA and anti-URYA groups were matched 1:1 using the nearest propensity score.

The outcomes included complications, changes in nutritional status, endoscopic findings and gastrointestinal quality of life index (GQLI) [9]. The complication was evaluated by Clavien-Dindo classification [10]. The change in nutritional status was evaluated by the relative values of body weight, hemoglobin, and albumin to the preoperative levels one year after surgery. The endoscopic findings 1 year after surgery were evaluated by the endoscopic 'residue, gastritis, bile' (RGB) classification proposed by Kubo [11], higher scores meant worse signs in the remnant stomach.

\section{Digestive reconstruction procedure}

After DG with D2 lymphadenectomy, which was following the Japanese gastric cancer treatment guidelines 2014 (ver. 4) [12], the duodenum was transected about $2 \mathrm{~cm}$ distal from the pylorus and the stomach was transected about $4-5 \mathrm{~cm}$ proximal to the tumor. A small entry was made at the jejunum on the antimesenteric border $20 \mathrm{~cm}$ distal to Treitz ligament. Another entry was made at the greater curvature side of posterior wall of gastric stump and $2 \mathrm{~cm}$ proximal to the stapling line of remnant stomach. The afferent Loop to lesser curvature for anti-URYA or the afferent loop to greater curvature for iso-URYA side-to-side gastrojejunostomy was performed using a 60-mm linear stapler with a blue cartridge. The "Braun enteroenterostomy" was performed by joining the afferent to efferent limb about 10 and $35 \mathrm{~cm}$ away from gastrointestinal anastomosis, respectively. The afferent intestine was blocked by ligation or stapler at about $3 \mathrm{~cm}$ away from gastrointestinal anastomosis and several interrupted seromuscular sutures was performed over the blocked site for permanent serosa-to-serosa adhesion (Fig. 2). All patients received antecolic gastrojejunostomy and remnant stomach was not fixed to transverse colon mesentery.

\section{Statistical method}

The continuous data were expressed as mean and standard error and the categorical data were expressed as numbers and proportions. Student t-test or Mann-Whitney $\mathrm{U}$ test was used to analyze the continuous data and the Pearson $\chi^{2}$ test or the Fisher's exact test was used to analyze the differences in the categorical data. All the statistical analysis was two tailed test and $P$ values $<0.05$ was considered to be statistically significant. All statistical analyses were performed using SPSS ver. 22 for Windows (SPSS Inc., Chicago, IL, USA).

\section{Result}

\section{Baseline data}

A total of 704 gastric cancer patients underwent DG in the period from January 2016 to December 2018. Of
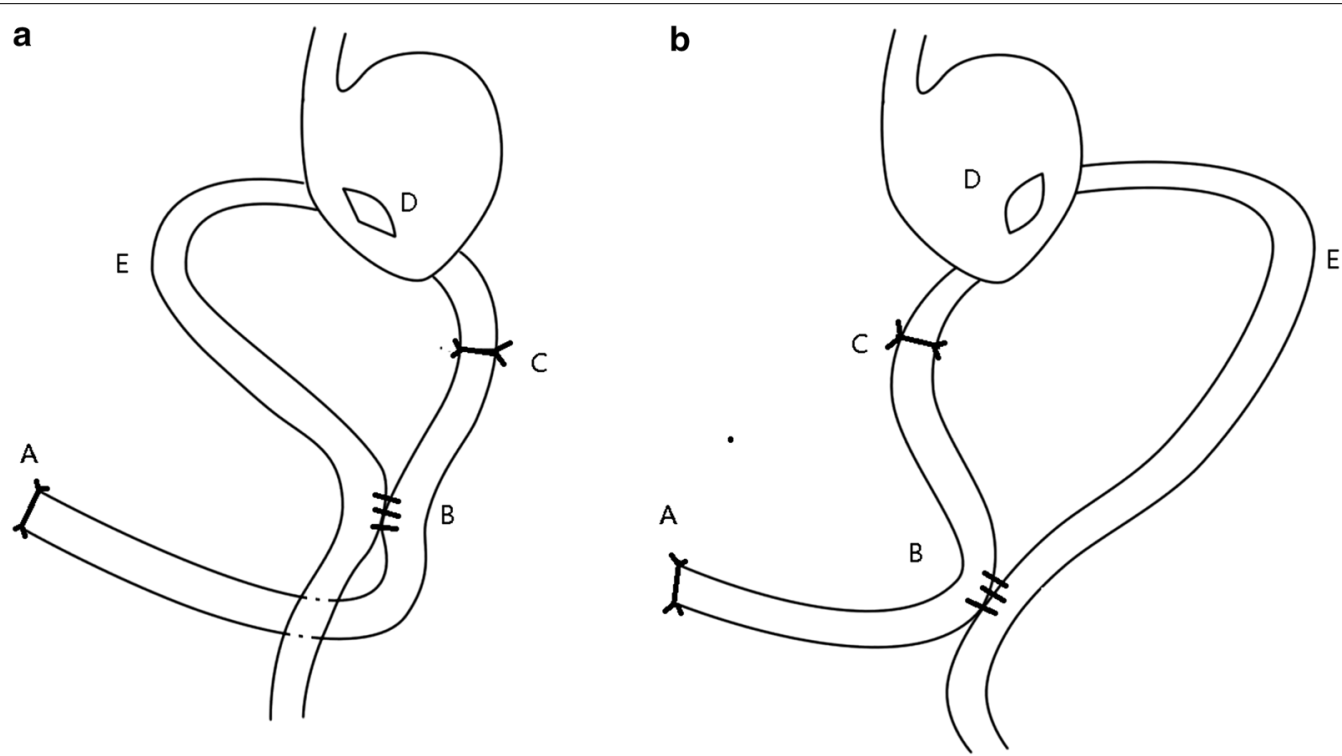

Fig. 2 Schematic diagram of uncut Roux-en-y anastomosis (URYA). URYA includes an end-to-side gastrojejunostomy which was constructed approximately $20 \mathrm{~cm}$ distal to Treitz ligament and a "Braun enteroenterostomy" which was performed by joining the afferent to efferent limb about 10 and $35 \mathrm{~cm}$ away from gastrointestinal anastomosis, respectively, and then the afferent limb was occluded $3 \mathrm{~cm}$ away from gastrointestinal anastomosis. a Represented iso-URYA and $\mathbf{b}$ represented anti-URYA. For both $\mathbf{a}, \mathbf{b}$, A represented duodenal stump; B represented Braun enteroenterostomy; C represented afferent occlusion; D represented gastrointestinal anastomosis; E represented efferent loop 
those, 92 patients were excluded due to combined organ resection or missing data. Finally, data of 612 patients were collected with 220 patients in anti-URYA group and 392 patients in iso-URYA group. Propensity score matching was performed with 15 covariates (sex, age, BMI, year of surgery, ASA score, patients' area and education, history of abdominal surgery, history of diabetes, history of smoking, tumor location, tumor size, preoperative chemotherapy, clinical $\mathrm{T}$ and $\mathrm{N}$ factor) and 183 patients from each group were matched 1:1 and no significant differences in baseline data were observed between two groups after PSM. The details were shown in Table 1.

\section{Operating findings and complications}

Operative findings, including operating time, blood loss, number of harvested lymph node surgery approach, stapler, postoperative hospital stay, did not differ significantly between two groups (Table 2). The method of occlusion of afferent loop was significantly different between two groups $(P=0.002)$. There were no significant differences in overall complication rates between two groups. The incidence of anastomotic bleeding was higher in the iso-URYA group, although it was not statistically significant $(2.2 \%$ in the anti-URYA group vs. $4.4 \%$ in the iso-URYA group, $\mathrm{P}=0.244$ ).

\section{Nutritional status, endoscopic findings and GQLI score}

The median follow-up time was 26.4 (13.6-42.3) months for iso-URYA group and 28.4 (14.6-44.7) months for anti-URYA group. Follow-up rate was $83.1 \%$ for antiURYA group and $85.3 \%$ for iso-URYA group. The nutritional status evaluated by the relative value of body weight, hemoglobin and albumin was not significantly different between two groups. The GQLI score in isoURYA group was higher than anti-URYA group, but the difference was not statistically significant $(P=0.104)$. $79.2 \%$ patients in anti-URYA group and $76.0 \%$ patients in iso-URYA group underwent endoscopic examination. Time interval between surgery and endoscopic examination was similar between two groups $(\mathrm{P}=0.726)$. Endoscopic evaluation of gastritis showed significantly different between two groups $(\mathrm{P}=0.036,30.4 \%$ for antiURYA and $21.5 \%$ for iso-URYA), while other two subitems did not differ significantly $(\mathrm{P}=0.432$ for residual food and $P=0.068$ for bile reflux). (Table 3.)

\section{Recanalization}

76 patients (ligation for 39 and stapler for 37) in antiURYA group and 68 patients (ligation for 47 and stapler for 21) in iso-URYA group underwent upper gastrointestinal contrast X-ray 1 year after surgery. 2.3\% recanalization $(2 / 86)$ was observed when the afferent loop was blocked by ligation while $22.4 \%$ (13/58) recanalization happened when the afferent loop was blocked by stapler. There were significant differences in recanalization rates between blocked by ligation and blocked by stapler, but there were no significantly differences in recanalization rates between iso- and anti-URYA group (Table 4).

\section{Discussion}

This research firstly compared iso- and anti-URYA after distal gastrectomy for gastric cancer. No differences were found between them in terms of short-term complications, nutritional status and quality of life 1 year after surgery. But endoscopic examination showed that anti-URYA group had more severe gastritis $(\mathrm{P}=0.036)$. More than $75 \%$ patients $(79.2 \%$ for anti-URYA and $76.0 \%$ for iso-URYA) had an endoscopic review in the similar period after surgery, and the result could be convincing. So the anti-URYA might be closely related to reflux gastritis. But our findings could offer another explanation. The recanalization rate was significantly higher after the luminal occlusion by stapler (Table 4), and the luminal occlusion by stapler had a larger proportion in anti-URYA group than iso-URYA group ( $44.8 \%$ vs $11.5 \%$, Table 2). So the anti-URYA group may have higher recanalization rate and further induce more severe gastritis. No significant differences in recanalization rates between iso- and anti-URYA group $(\mathrm{P}=0.554$, Table 4$)$ was probably because the proportion of patients who underwent contrast X-ray was insufficient $(41.5 \%$ for anti-URYA group and $37.2 \%$ for iso-URYA group).

Little attention was paid to the orientation of peristalsis in previous studies [13-15]. In our institution, the orientation of peristalsis of URYA is mainly determined by surgeon's personal preference. Surgeons who support anti-URYA argue that iso-URYA has a relatively limited and fixed space between gastrointestinal anastomosis and transverse mesentery and may further increase the incidence of internal hernia. Surgeons who support isoURYA argue that anti-URYA transects the short gastric artery and may induce gastric stump ischemia. These arguments may exist but our study found no difference in short-term outcomes between two groups. So far, no RCTs focus on this problem. In this retrospective cohort study, we identified sufficient clinically essential covariates from among preoperative variables to maximize the comparability between iso- and anti-groups as far as possible. This methodology using actual clinical data with strict PSM may compensate for RCTs in the context of rapid developments in surgical treatment $[16,17]$.

The anastomotic bleeding was more common in iso-URYA comparing with anti-URYA $(4.4 \%$ vs $2.2 \%$, $\mathrm{P}=0.240$ ), presumably because of the higher proportion of circular stapler use in iso-URYA group. Circular stapler has poor hemostatic effects by tissue squeezing 
Table 1 Baseline data before and after propensity score matching

\begin{tabular}{|c|c|c|c|c|c|c|c|c|c|c|}
\hline \multirow[t]{3}{*}{ Characteristics } & \multicolumn{5}{|c|}{ Before matching } & \multicolumn{5}{|c|}{ After matching } \\
\hline & \multicolumn{2}{|c|}{ ANTI $(n=220)$} & \multicolumn{2}{|c|}{ ISO (n=392) } & \multirow[t]{2}{*}{$\mathbf{P}$} & \multicolumn{2}{|c|}{ ANTI $(n=183)$} & \multicolumn{2}{|c|}{ ISO $(n=183)$} & \multirow[t]{2}{*}{$P$} \\
\hline & $\mathrm{n}$ & $\%$ & $n$ & $\%$ & & $n$ & $\%$ & $\mathrm{n}$ & $\%$ & \\
\hline \multicolumn{11}{|l|}{ Sex } \\
\hline Male & 139 & 63.2 & 243 & 62.0 & 0.77 & 116 & 63.4 & 114 & 62.3 & 0.829 \\
\hline Female & 81 & 36.8 & 149 & 38.0 & & 67 & 36.6 & 69 & 37.7 & \\
\hline Age (mean $\pm S D$, year) & 63.3 & \pm 8.6 & 65.6 & \pm 8.4 & & 64.3 & \pm 8.7 & 64.9 & \pm 8.5 & 0.563 \\
\hline $\mathrm{BMI}\left(\right.$ mean $\left.\pm \mathrm{SD}, \mathrm{kg} / \mathrm{m}^{2}\right)$ & 24.9 & \pm 4.4 & 25.2 & \pm 4.3 & & 24.5 & \pm 4.3 & 24.8 & \pm 4.5 & 0.623 \\
\hline \multicolumn{11}{|l|}{ Year of surgery } \\
\hline 2016 & 43 & 19.6 & 118 & 30.1 & 0.011 & 28 & 15.3 & 34 & 18.6 & 0.326 \\
\hline 2017 & 92 & 41.8 & 155 & 39.5 & & 67 & 36.6 & 75 & 41.0 & \\
\hline 2018 & 85 & 38.6 & 119 & 30.4 & & 88 & 48.1 & 74 & 40.4 & \\
\hline \multicolumn{11}{|l|}{ ASA score } \\
\hline 1 & 70 & 31.8 & 90 & 23.0 & 0.045 & 49 & 26.8 & 50 & 27.3 & 0.992 \\
\hline$\|$ & 109 & 49.5 & 210 & 53.6 & & 98 & 53.6 & 97 & 53.0 & \\
\hline III & 41 & 18.6 & 92 & 23.5 & & 36 & 19.7 & 36 & 19.7 & \\
\hline \multicolumn{11}{|l|}{ Area } \\
\hline Urban & 95 & 43.2 & 206 & 52.6 & 0.026 & 86 & 47.0 & 85 & 46.4 & 0.917 \\
\hline Rural & 125 & 56.8 & 186 & 47.4 & & 97 & 53.0 & 98 & 53.6 & \\
\hline \multicolumn{11}{|l|}{ Education (years) } \\
\hline$<12$ & 41 & 18.6 & 99 & 25.3 & 0.061 & 39 & 21.3 & 37 & 20.2 & 0.797 \\
\hline$\geq 12$ & 179 & 81.4 & 293 & 74.7 & & 144 & 78.7 & 146 & 79.8 & \\
\hline \multicolumn{11}{|c|}{ History of abdominal surgery } \\
\hline Yes & 120 & 54.5 & 198 & 50.5 & 0.338 & 107 & 58.5 & 105 & 57.4 & 0.832 \\
\hline No & 100 & 45.5 & 194 & 49.5 & & 76 & 41.5 & 78 & 42.6 & \\
\hline \multicolumn{11}{|l|}{ History of diabetes } \\
\hline Yes & 83 & 37.7 & 132 & 33.7 & 0.313 & 75 & 41.0 & 70 & 38.9 & 0.686 \\
\hline No & 137 & 62.3 & 260 & 66.3 & & 108 & 59.0 & 113 & 61.1 & \\
\hline \multicolumn{11}{|l|}{ History of smoking } \\
\hline Yes & 83 & 37.7 & 168 & 42.9 & 0.216 & 53 & 29.0 & 59 & 32.2 & 0.496 \\
\hline No & 137 & 62.3 & 224 & 57.1 & & 130 & 71.0 & 124 & 67.8 & \\
\hline \multicolumn{11}{|l|}{ Tumor location } \\
\hline Gastric body & 79 & 35.9 & 99 & 25.3 & 0.020 & 56 & 26.8 & 44 & 24.0 & 0.331 \\
\hline Between & 96 & 43.6 & 197 & 50.3 & & 92 & 53.6 & 97 & 53.0 & \\
\hline Pyloric canal & 45 & 20.5 & 96 & 24.5 & & 35 & 19.7 & 42 & 23.0 & \\
\hline \multicolumn{11}{|l|}{ Tumor size $(\mathrm{cm})$} \\
\hline$<4$ & 123 & 57.7 & 259 & 66.1 & 0.040 & 108 & 59.0 & 98 & 53.6 & 0.292 \\
\hline$\geq 4$ & 97 & 42.3 & 133 & 33.9 & & 75 & 41.0 & 85 & 46.4 & \\
\hline Preoperative chemothera & & & & & & & & & & \\
\hline Yes & 21 & 9.5 & 22 & 5.6 & 0.068 & 14 & 92.3 & 15 & 92.4 & 0.847 \\
\hline No & 199 & 90.5 & 370 & 94.4 & & 169 & 7.7 & 168 & 7.6 & \\
\hline Clinical T factor & & & & & & & & & & \\
\hline $\mathrm{T} 1$ & 58 & 26.4 & 73 & 18.6 & 0.009 & 41 & 22.4 & 42 & 23.0 & 0.342 \\
\hline $\mathrm{T} 2$ & 46 & 20.9 & 99 & 25.3 & & 44 & 24.0 & 31 & 16.9 & \\
\hline $\mathrm{T} 3$ & 52 & 23.6 & 130 & 33.2 & & 43 & 23.5 & 53 & 29.0 & \\
\hline $\mathrm{T} 4$ & 64 & 29.1 & 90 & 23.0 & & 55 & 30.1 & 57 & 31.1 & \\
\hline Clinical N factor & & & & & & & & & & \\
\hline No & 101 & 45.9 & 219 & 55.9 & 0.018 & 80 & 43.7 & 92 & 50.3 & 0.209 \\
\hline N1-3 & 119 & 54.1 & 173 & 44.1 & & 103 & 56.3 & 91 & 49.7 & \\
\hline
\end{tabular}

ANTI antiperistaltic uncut Roux-en-Y anastomosis, ISO Isoperistaltic uncut Roux-en-Y anastomosis 
Table 2 Operating finding and complication

\begin{tabular}{|c|c|c|c|c|c|}
\hline & \multicolumn{2}{|c|}{ ANTI $(n=183)$} & \multicolumn{2}{|c|}{ ISO $(n=183)$} & \multirow[t]{2}{*}{$\mathbf{P}$} \\
\hline & $\mathrm{n}$ & $\%$ & $\mathrm{n}$ & $\%$ & \\
\hline Mean operation time, mean $\pm S D$, min & 251.5 & \pm 46.4 & 263.1 & \pm 46.8 & 0.735 \\
\hline Mean blood loss, mean $\pm \mathrm{SD}, \mathrm{ml}$ & 239.6 & \pm 32.4 & 222.5 & \pm 35.3 & 0.492 \\
\hline Transfusion & 7 & 3.8 & 9 & 4.9 & 0.617 \\
\hline Harvested lymph node, median (min, max) & $29(17-54)$ & & $31(16-57)$ & & 0.565 \\
\hline RO & 176 & 96.2 & 174 & 95.1 & 0.609 \\
\hline \multicolumn{6}{|l|}{ Surgery approach } \\
\hline LAG & 90 & 49.2 & 76 & 41.5 & \multirow[t]{2}{*}{0.142} \\
\hline OG & 93 & 50.8 & 107 & 58.5 & \\
\hline \multicolumn{6}{|l|}{ Stapler } \\
\hline Circular & 49 & 26.8 & 61 & 33.3 & \multirow[t]{2}{*}{0.171} \\
\hline Linear & 134 & 73.2 & 122 & 66.7 & \\
\hline \multicolumn{6}{|l|}{ Occlusion of afferent loop } \\
\hline Ligation & 101 & 55.2 & 162 & 88.5 & \multirow[t]{2}{*}{0.001} \\
\hline Stapler & 82 & 44.8 & 21 & 11.5 & \\
\hline \multicolumn{6}{|l|}{ Pathological stage } \\
\hline Stage $1 a$ & 14 & 7.7 & 8 & 4.4 & \multirow[t]{7}{*}{0.868} \\
\hline Stage $1 b$ & 25 & 13.7 & 23 & 12.6 & \\
\hline Stage 2a & 35 & 19.1 & 36 & 19.7 & \\
\hline Stage $2 b$ & 36 & 19.7 & 37 & 20.2 & \\
\hline Stage $3 a$ & 29 & 15.8 & 34 & 18.6 & \\
\hline Stage $3 b$ & 30 & 16.4 & 28 & 15.3 & \\
\hline Stage $3 c$ & 14 & 7.7 & 17 & 9.3 & \\
\hline Postoperative hospital stay, mean $\pm S D$, days & 7.7 & \pm 3.7 & 8.2 & \pm 4.3 & 0.312 \\
\hline \multicolumn{6}{|l|}{ Complication $^{\mathrm{a}}$} \\
\hline Grade 1 & 39 & 37.1 & 36 & 34.6 & \multirow[t]{5}{*}{0.792} \\
\hline Grade 2 & 30 & 28.6 & 32 & 30.8 & \\
\hline Grade 3 & 27 & 25.7 & 25 & 24.0 & \\
\hline Grade 4 & 9 & 8.6 & 10 & 9.6 & \\
\hline Grade 5 & 0 & 0.0 & 1 & 1.0 & \\
\hline \multicolumn{6}{|l|}{ Early-phase complication } \\
\hline Incision infection & 9 & 4.9 & 6 & 3.3 & 0.306 \\
\hline Duodenum stump leak & 1 & 0.5 & 1 & 0.5 & 1.000 \\
\hline Anastomotic leak & 1 & 0.5 & 0 & 0.0 & 1.000 \\
\hline Anastomotic bleeding & 4 & 2.2 & 8 & 4.4 & 0.244 \\
\hline Intra-abdominal bleeding & 2 & 1.1 & 2 & 1.1 & 1.000 \\
\hline Intra-abdominal infection & 9 & 4.9 & 8 & 3.8 & 0.804 \\
\hline Delayed gastric emptying & 1 & 0.5 & 2 & 1.1 & 0.562 \\
\hline Pancreatic fistula & 10 & 5.5 & 5 & 2.7 & 0.187 \\
\hline \multicolumn{6}{|l|}{ Late-phase complication } \\
\hline Bowel obstruction & 8 & 4.4 & 7 & 3.8 & 0.792 \\
\hline Internal hernia & 3 & 1.6 & 2 & 1.1 & 0.652 \\
\hline Anastomotic stricture & 0 & 0.0 & 0 & 0.0 & 1.000 \\
\hline Reoperation & 2 & 1.1 & 2 & 1.1 & 1.000 \\
\hline Mortality in 30 days & 0 & 0.0 & 1 & 0.5 & 1.000 \\
\hline Adjuvant chemotherapy & 129 & 66.1 & 134 & 71.6 & 0.309 \\
\hline
\end{tabular}

${ }^{a}$ Clavien-Dindo classification 
Table 3 Nutritional status, endoscopic findings and GQLI score one year after surgery

\begin{tabular}{|c|c|c|c|c|c|}
\hline & \multicolumn{2}{|c|}{ ANTI $(n=183)$} & \multicolumn{2}{|c|}{ ISO $(n=183)$} & \multirow[t]{2}{*}{$\mathbf{P}$} \\
\hline & $\mathbf{n}$ & $\%$ & $\mathbf{n}$ & $\%$ & \\
\hline Follow-up rate & 152 & 83.1 & 156 & 85.3 & \\
\hline Body weight, mean $\pm S D^{a}$ & 90.7 & \pm 8.4 & 91.1 & \pm 7.9 & 0.659 \\
\hline Hemoglobin, mean $\pm \mathrm{SD}^{\mathrm{a}}$ & 97.2 & \pm 7.5 & 96.9 & \pm 8.1 & 0.457 \\
\hline Albumin, mean $\pm S D^{a}$ & 104.3 & \pm 9.5 & 105.2 & \pm 10.1 & 0.334 \\
\hline Endoscopic findings & 145 & 79.2 & 139 & 76.0 & \\
\hline Interval, month, mean $\pm S D^{b}$ & 16.1 & \pm 2.5 & 15.6 & \pm 3.3 & 0.726 \\
\hline \multicolumn{6}{|l|}{ Residual food } \\
\hline Grade 0 & 114 & 78.6 & 99 & 71.2 & 0.432 \\
\hline Grade 1 & 13 & 9.0 & 18 & 12.9 & \\
\hline Grade 2 & 11 & 7.6 & 16 & 11.5 & \\
\hline Grade 3 & 7 & 4.8 & 6 & 4.3 & \\
\hline Grade 4 & 0 & 0.0 & 0 & 0.0 & \\
\hline \multicolumn{6}{|l|}{ Gastritis } \\
\hline Grade 0 & 101 & 69.7 & 109 & 78.4 & 0.036 \\
\hline Grade 1 & 29 & 20.0 & 28 & 20.1 & \\
\hline Grade 2 & 13 & 9.0 & 2 & 1.4 & \\
\hline Grade 3 & 1 & 0.7 & 0 & 0 & \\
\hline Grade 4 & 1 & 0.7 & 0 & 0 & \\
\hline \multicolumn{6}{|l|}{ Bile reflux } \\
\hline Grade 0 & 101 & 69.7 & 110 & 79.1 & 0.068 \\
\hline Grade 1 & 44 & 30.3 & 29 & 20.9 & \\
\hline GQLI score, mean \pm SD & 108.8 & \pm 18.5 & 112.5 & \pm 17.2 & 0.104 \\
\hline
\end{tabular}

and the following anastomotic reinforcement by suture may also increase anastomotic bleeding [18, 19]. An increased incidence of pancreatic fistula in anti-URYA group may be related to higher proportion of LAG (5.5\% vs $2.7 \%, \mathrm{P}=0.187)$. The possible reasons included intraoperative compression of the pancreas with long straight instruments, an inappropriate dissection plane along the pancreas, or thermal damage to the pancreas by energy devices in LAG [17].
URYA can divert biliary and pancreatic secretions away from the remnant stomach more efficiently by blocking the afferent loop and further prevent inflammation and even carcinogenesis of the remnant stomach and esophagus [3-5, 20, 21]. However, the recanalization of the jejunum after surgery may nullify this benefit. The luminal recanalization is caused by the failure of a fibrous healing process between the approximated mucosal surfaces $[6,22]$. In this study, two methods, 0 \# non-absorbable suture or no-knife linear cutter, were used to block the afferent loop. Only 2 out of 86 had recanalization for the former. 13 out of 58 had recanalization for the latter, of which 2 used 6-row linear stapler and 11 used 3-row linear stapler. So it seems that non-absorbable suture is more suitable for the luminal occlusion basing on the lower recanalization rate comparing with 3-row linear cutter and lower economic costs comparing with 6-row linear cutter. Our experience is that the ligation should be enough to block but not cut the small bowel. Too loose or too tight ligation both can induce early recanalization.

It cannot be denied that the present study had some important limitations. First, it was still retrospective in nature even after very strict PSM. There is no guarantee that all confounding factors were included in our analyses. RCTs will be necessary to assess the accuracy of this type of study. Second, this was a single center study. Therefore, we should be careful when extrapolating our results to all institutions. Third, this study could not survey postoperative symptoms severity. Assessment of subjective symptoms with a well-designed questionnaire might reveal the differences between two groups on early oral feeding or postprandial discomfort.

\section{Conclusion}

In conclusion, the iso-URYA and anti-URYA group present similar results in short term outcomes. The isoURYA group had lower rate of severe gastritis comparing with anti-URYA group, and the reason lies in the higher proportion of ligation blocking afferent loop in iso-URYA group which leads to lower recanalization rate.

Table 4 Recanalization

\begin{tabular}{|c|c|c|c|c|c|c|c|}
\hline \multirow[t]{2}{*}{ Recanalization } & \multicolumn{3}{|c|}{ ANTI $(n=76)$} & \multicolumn{3}{|c|}{ ISO $(n=68)$} & \multirow[t]{2}{*}{$P$} \\
\hline & Ligation & Stapler & $P$ & Ligation & Stapler & $P$ & \\
\hline YES & 1 & 8 & $0.013^{\mathrm{a}}$ & 1 & 5 & $0.009^{a}$ & 0.554 \\
\hline NO & 38 & 29 & & 46 & 16 & & \\
\hline
\end{tabular}

${ }^{a}$ Fisher's exact 


\section{Abbreviations}

URYA: Uncut Roux-en-y anastomosis; iso-URYA: Isoperistaltic URYA; antiURYA: Antiperistaltic URYA; DG: Distal gastrectomy; GC: Gastric cancer; PSM: Propensity score matching; BMI: Body mass index; LAG: Laparoscopic assisted gastrectomy.

\section{Acknowledgements}

Not applicable.

\section{Authors' contributions}

The contribution of each author to this paper was listed below: FGE (Conceptualization, Methodology); CHT (Data collection, Writing-Original draft preparation); HHB (Data collection, Reviewing and Editing); LTH (Software, Validation); YXY (Research assistant, Validation). All authors read and approved the final manuscript.

\section{Funding}

This study was funded by the National Natural Science Foundation of China (Grant No. 81372048). The funder provided consulting fees and publishing fees for the study.

\section{Availability of data and materials}

The datasets used during the current study are available from the corresponding author on reasonable request.

\section{Ethics approval and consent to participate}

Authorization of the ethical board was not required for this retrospective investigation, but signed consent for surgical treatment and research purposes was obtained before surgical procedures.

\section{Consent to publish}

Not applicable.

\section{Competing interests}

The authors declare no conflicts of interest in association with the present study.

\section{Author details}

1 Department of Gastrointestinal Surgery, Changhai Hospital, The Second Military Medical University, Shanghai 200433, China. ${ }^{2}$ Department of Gastroenterology, Changhai Hospital, The Second Military Medical University, Shanghai 200433, China. ${ }^{3}$ Department of General Surgery, Changhai Hospital, No.168 Changhai Road, Yangpu District, Shanghai 200433, China.

Received: 28 June 2020 Accepted: 29 October 2020

Published online: 07 November 2020

\section{References}

1. Bray F, Ferlay J, Soerjomataram I, Siegel RL, Torre LA, Jemal A. Global cancer statistics 2018: GLOBOCAN estimates of incidence and mortality worldwide for 36 cancers in 185 countries. CA Cancer J Clin. 2018;68(6):394-424.

2. Ajani JA, D'Amico TA, Almhanna K, Bentrem DJ, Chao J, Das P, et al. Gastric Cancer, Version 3. 2016, NCCN Clinical Practice Guidelines in Oncology. J Natl Compr Cancer Netw. 2016;14(10):1286-312.

3. Park JY, Kim YJ. Uncut RouX-en-Y reconstruction after laparoscopic distal gastrectomy can be a favorable method in terms of gastritis, bile reflux, and gastric residue. J Gastric Cancer. 2014;14(4):229-37.

4. Sun MM, Fan YY, Dang SC. Comparison between uncut RouX-en-Y and Roux-en-Y reconstruction after distal gastrectomy for gastric cancer: a meta-analysis. World J Gastroenterol. 2018;24(24):2628-39.

5. Yang D, He L, Tong WH, Jia ZF, Su TR, Wang Q. Randomized controlled tria of uncut RouX-en-Y vs Billroth II reconstruction after distal gastrectomy for gastric cancer: which technique is better for avoiding biliary reflux and gastritis? World J Gastroenterol. 2017;23(34):6350-6.

6. Park YS, Shin DJ, Son SY, Kim KH, Park DJ, Ahn SH, et al. Roux stasis syndrome and gastric food stasis after laparoscopic distal gastrectomy with Uncut Roux-en-Y reconstruction in gastric cancer patients: a propensity score matching analysis. World J Surg. 2018;42(12):4022-32.

7. Ma JJ, Zang L, Yang A, Hu WG, Feng B, Dong F, et al. A modified uncut Roux-en-Y anastomosis in totally laparoscopic distal gastrectomy: preliminary results and initial experience. Surg Endosc. 2017:31(11):4749-55.

8. Zhang YM, Liu XL, Xue DB, Wei YW, Yun XG. Myoelectric activity and motility of the Roux limb after cut or uncut Roux-en-Y gastrojejunostomy. World J Gastroenterol. 2006;12(47):7699-704.

9. Nickel F, Schmidt L, Bruckner T, Billeter AT, Kenngott HG, Muller-Stich BP, et al. Gastrointestinal quality of life improves significantly after sleeve gastrectomy and Roux-en-Y gastric bypass-a prospective cross-sectional study within a 2-year follow-up. Obes Surg. 2017;27(5):1292-7.

10. Clavien PA, Barkun J, de Oliveira ML, Vauthey JN, Dindo D, Schulick RD, et al. The Clavien-Dindo classification of surgical complications: five-year experience. Ann Surg. 2009;250(2):187-96.

11. Kubo M, Sasako M, Gotoda T, Ono H, Fujishiro M, Saito D, et al. Endoscopic evaluation of the remnant stomach after gastrectomy: proposal for a new classification. Gastric Cancer. 2002;5(2):83-9.

12. Japanese gastric cancer treatment guidelines 2014 (ver. 4). Gastric Cancer. 2017:20(1):1-19.

13. Mon RA, Cullen JJ. Standard Roux-en-Y gastrojejunostomy vs "uncut" Roux-en-Y gastrojejunostomy: a matched cohort study. J Gastrointest Surg. 2000;4(3):298-303.

14. Yang L, Xu H, Zhang DC, Li FY, Wang WZ, Li Z, et al. Uncut Roux-en-Y reconstruction in a laparoscopic distal gastrectomy: a single-center study of 228 consecutive cases and short-term outcomes. Surg Innov. 2019;26(6):698-704

15. Chaiyasate K, Jacobs M, Brooks SE, del Rosario G, Andrus L, Kestenberg W, et al. The uncut Roux-en-Y with jejunal pouch: a new reconstruction technique for total gastrectomy. Surgery. 2007;142(1):33-9.

16. Honda M, Hiki N, Kinoshita T, Yabusaki H, Abe T, Nunobe S, et al. Longterm outcomes of laparoscopic versus open surgery for clinical stage I gastric cancer: the LOC-1 study. Ann Surg. 2016;264(2):214-22.

17. Kinoshita T, Uyama I, Terashima M, Noshiro H, Nagai E, Obama K, et al. Long-term outcomes of laparoscopic versus open surgery for clinical stage II/III gastric cancer: a multicenter cohort study in Japan (LOC-a study). Ann Surg. 2018;269(5):887-94.

18. Liao T, Deng L, Yao X, Ouyang M. Comparison of the safety and efficacy between linear stapler and circular stapler in totally laparoscopic total gastrectomy: protocol for a systematic review and meta-analysis. BMJ Open. 2019;9(5):e028216.

19. Kawamura H, Ohno Y, Ichikawa N, Yoshida T, Homma S, Takahashi M, et al. Anastomotic complications after laparoscopic total gastrectomy with esophagojejunostomy constructed by circular stapler (OrVil()) versus linear stapler (overlap method). Surg Endosc. 2017;31(12):5175-82.

20. Nishijima K, Miwa K, Miyashita T, Kinami S, Ninomiya I, Fushida S, et al. Impact of the biliary diversion procedure on carcinogenesis in Barrett's esophagus surgically induced by duodenoesophageal reflux in rats. Ann Surg. 2004:240(1):57-67.

21. Uyama I, Sakurai Y, Komori Y, Nakamura Y, Syoji M, Tonomura S, et al. Laparoscopy-assisted uncut Roux-en-Y operation after distal gastrectomy for gastric cancer. Gastric Cancer. 2005;8(4):253-7.

22. Tu BN, Sarr MG, Kelly KA. Early clinical results with the uncut Roux reconstruction after gastrectomy: limitations of the stapling technique. Am J Surg. 1995;170(3):262-4.

\section{Publisher's Note}

Springer Nature remains neutral with regard to jurisdictional claims in published maps and institutional affiliations. 